\title{
PRÁTICAS DISCURSIVAS NO ÂMBITO DA FORMAÇÃO DO PROFESSOR
}

\author{
Iramaia da Silva SANTOS \\ (Universidade do Estado da Bahia) \\ maias@hotmail.com
}

\begin{abstract}
Resumo: Este trabalho analisa os rumos da carreira profissional docente no viés da formação continuada e suas consequências na construção de saberes, práticas pedagógicas e construção de sentidos atribuídos ao professor e como isso implica na construção da identidade docente. Uma das preocupações das políticas de formação continuada do professor é avaliar suas competências, pois são consideradas enquanto dimensões de trabalho que subsidiam a prática profissional docente. Neste estudo, utilizou-se o aporte teórico da Análise do Discurso que desvela as marcas discursivas e ideológicas que envolvem o campo da formação docente. Desse modo, conclui-se que os sentidos de competência e certificação que hoje vigoram no mercado de trabalho atribuem tendências e implicações ideológicas diretamente impressas sobre o modo como são construídos os papéis e funções sociais da atividade profissional do professor. Dessa maneira, a visão discursiva da competência encontra-se permeada por adventos que monopolizam a prática pedagógica do professor, vista apenas como uma função a ser realizada com aptidão.
\end{abstract}

Palavras-Chave: Formação continuada do professor. Competência. Práticas discursivas.

Abstract: This paper analyzes the direction of teacher professional career in continuing education and its consequences in the construction of knowledge, pedagogical practices and construction of meanings attributed to teacher and how it entails the construction regarding the teacher identity. One of the concerns of continued education policies of the teacher is to assess his/her skills, since they are considered as dimensions of work that support the teaching professional practice. In this study, we used the theoretical framework of discourse analysis that reveals the discursive and ideological implications involving the field of teacher education. Thus, it is concluded that the sense of competence and certification that stands today in the labor market points to trends and ideological implications directly related on how the social roles and functions of the professional activity of teachers are constructed. Thus, the vision of discursive competence is permeated by advents that monopolize the teacher's pedagogic practice that is seen only as a function to be performed with skill.

Keywords: Continuing education teacher. Competence. discursive practices. 


\section{Introdução}

Atualmente as exigências do mundo do trabalho exprimem e produzem nos profissionais docentes uma necessidade de aprimoramento constante. Estes aspectos têm influenciado a formação contínua dos professores no que se refere ao empreendimento dado à racionalidade técnica da formação docente. (SHÖN, 1992). Esse enfoque segue uma "concepção epistemológica da prática, herdada do positivismo, que prevaleceu ao longo do século $\mathrm{XX}$, servindo de referência para a educação e socialização dos profissionais em geral e dos docentes em particular”. (GÓMEZ, 1992, p.26).

Segundo Davinini (1995, p. 103), "este modelo reforçou a visão da prática como campo objetivo e neutral sobre o qual se opera pela instrumentalização de técnicas e procedimentos universalistas". Dentro desta concepção, a competência profissional do professor resume-se ao conhecimento da disciplina, objeto de estudo, e no domínio das formas didáticas a fim de transmiti-las. Segundo Ribas, (1997, p.39):

O tipo de formação que o Governo vem oferecendo aos professores da rede pública não tem surtido efeito, uma vez que não existe uma política séria de capacitação, e sim propostas de Estado, sempre sem continuidade, que não atendem às necessidades reais da escola e dos professores por serem descontextualizadas e por terem como fim último a aplicação política de verba pública destinada para este fim.

A autora aborda, nessa seção, a inexistência de uma política pública de formação docente que esteja atenta às reais condições de trabalho do professor. A descontextualização e descontinuidade de propostas governamentais para a formação do professor são algumas das consequências apontadas pela autora que configuram o modo como é tratado o profissional docente. Almeida (2001, p. 07) afirma que:

Como a prática do professor [profissional da educação] desenvolve-se na escola, a sua melhora profissional leva ao desenvolvimento da instituição e vice-versa. As escolas não podem mudar sem o empenhamento dos professores; e estes não podem mudar sem uma transformação das instituições em que trabalham. $O$ desenvolvimento profissional dos professores tem de estar articulado com as escolas e os seus projetos.

Esta reflexão revela a visão sobre a formação do sujeito-professorprofissional reflexivo que 
deverá ser capaz de estabelecer relações com o espaço escolar como um todo e com seus pares, fazendo com que os conhecimentos teóricos e a prática sejam adequados às exigências de sua atividade profissional, em um processo contínuo de desenvolvimento. (ALMEIDA, 2008, p.48).

Nesse sentido, a docência é entendida como o caminho à prática reflexiva. Para Dewey (1959) o pensamento reflexivo é a espécie de pensamento que consiste em examinar, mentalmente, o assunto e dar-lhe consideração séria e consecutiva. Contudo, a reflexão não é simplesmente uma sequência, mas uma consequência, uma ordem de tal modo consecutiva que as partes sucessivas de um pensamento reflexivo derivam umas das outras e sustentam-se umas às outras.

Dessa forma, para Ribas (1997), uma nova competência pedagógica nasce no âmbito escolar, a partir do estudo da própria prática, desvelando-a, no movimento dialético ação-reflexão-ação. De tal modo, "evita-se a dicotomia teoria/prática, bem como a justaposição ou a associação, que transformaria o trabalho num procedimento funcional, operativo. O que se objetiva, portanto, é a construção de uma prática pedagógica plena, crítica e criativa" (RIBAS, 1997, p. 50). Nesse sentido, a competência docente deve conectar-se com a atividade profissional, ou seja, com a carreira profissional construída coletivamente e o percurso individual do professor na formação docente. Essa conexão é concretizada pela representação social, cultural e profissional do professor acerca do significado e sentido do seu papel e função.

Nesta perspectiva, o presente estudo pretende contribuir com a ampliação das reflexões sobre a formação continuada dos professores a partir dos discursos gerados no atual contexto sobre a construção da identidade do professor, seus sentidos e representações. Desse modo, a finalidade deste trabalho é propor uma análise acerca dos rumos da carreira profissional docente, no viés da formação continuada, e suas consequências na construção de saberes, práticas pedagógicas e construção de sentidos atribuídos ao professor e de como isso implica na construção da identidade docente e nas representações que dela são geradas. 


\section{Certificação e competências no âmbito da formação profissional docente}

O forte movimento que impulsiona os setores econômicos pela modernização e competitividade em todo o mundo capitalista vem acompanhado da transformação das identidades profissionais, individuais e coletivas, da construção de novas competências, do aumento persistente do desemprego, da precarização do trabalho e da exclusão social. (MORAES ; NETO, 2005).

Nesse sentido, pode-se dizer que o processo de globalização econômica e as grandes inovações tecnológicas introduzidas no trabalho têm promovido mudanças nos perfis de qualificação profissional dos trabalhadores e incidido sobre sua educação/formação.

Nesse sentido, Moraes e Neto (2005, p.1445) afirmam que:

As políticas de formação devem estar integradas ao conjunto das políticas públicas voltadas para o desenvolvimento econômico e social do país, devendo ser garantidas, ao longo da vida, e em bases contínuas, a todas as categorias de trabalhadores, empregados e desempregados.

Assim sendo, a organização de uma política pública nacional de certificação profissional seria uma maneira de viabilizar aos trabalhadores a possibilidade de gerir seu itinerário formativo, proporcionando-Ihes certificados com validade no mercado de trabalho e, também, "intercambiáveis aos títulos e diplomas escolares" (FIDALGO, 2003, p.134). Nessa perspectiva, a certificação é entendida como "o reconhecimento social dos conhecimentos, habilidades e competências construídos na vida, no trabalho, e nas lutas sociais do (a) trabalhador (a)". (LIMA, 2003, p.36).

A construção da vida profissional é "uma construção contínua da pessoa humana, dos seus saberes e aptidões, da sua capacidade de discernir e agir" (DELORS, 2004, p.18). Nesse sentido, a noção de competência surge para designar os novos requisitos exigidos pelas recentes transformações nos setores produtivos, no novo paradigma organizacional da produção flexível. (MORAES; NETO, 2005).

No âmbito das políticas de formação profissional de professores, Mourão (2003, p.265) afirma: 
A lógica da competência é evidenciada na Portaria no. 1.403, de 9 de junho de 2003, que institui o Sistema Nacional de Certificação e Formação Continuada de Professores. O documento ao legislar sobre a certificação está centrado na formação que privilegia os percursos individualizados de qualificação, ao mesmo tempo em que estipula as competências necessárias ao desenvolvimento profissional.

Dessa forma, a autora enfatiza a tendência individualista e técnica da formação profissional do professor, vigente nas diretrizes da política pública educacional do Sistema Nacional de Certificação e Formação Continuada de Professores.

De acordo com Shiroma (2003, p.85) "o projeto de formação docente é tomado como elemento importante para a recomposição da hegemonia dominante". Assim, o que está em jogo é o controle do trabalho docente, já que o currículo por competência está longe de ser emancipador, pois a ação imediatista de responder a eventos fragmenta a formação e desintegra o currículo. (MOURÃO, 2003). Esse entendimento privilegia a competência técnica individualizada e acarreta consequências como a desvalorização dos conhecimentos construídos com a experiência adquirida na prática profissional e, por conseguinte, uma supervalorização dos conhecimentos tácitos, que acabam sendo regulados por instituições e processos estatais.

Todavia, Moraes e Neto (2005, p.1453) afirmam que para a construção de uma política pública de certificação profissional é necessário

garantir que a certificação seja o resultado de uma construção coletiva, tornando inadiável o estabelecimento da negociação de toda ação formativa e de certificação entre trabalhadores e empregadores. [...] a participação de todos os atores sociais envolvidos no campo da certificação profissional como um dos elementos mais importantes para garantir os princípios da legitimidade, confiabilidade, validade e credibilidade dos processos certificadores.

Nessa perspectiva, apreende-se a ideia de que a certificação não deve ser tratada apenas como resultado de um processo atribuído de forma vertical ao trabalhador. $\mathrm{O}$ que se propõe é a conquista de uma política que incentive o (a) trabalhador (a) a participar efetivamente de ações que priorizem a qualidade na formação profissional que tornem legítimos os processos de certificação profissional.

Deste modo, qualificação ou competência devem ser frutos de negociação/consenso social, como forma de construção social. Assim, segundo 
Moraes e Neto (2005) o sistema de certificação profissional deve se constituir como construção coletiva, viabilizar a participação dos trabalhadores na definição dos perfis profissionais, dos processos formativos, dos critérios e dos procedimentos da certificação profissional.

Portanto, essas considerações apontam para a ideia de que a certificação e a competência no âmbito da formação profissional estão carregadas pelo ideário da ascensão e progresso que o sistema neoliberal difunde, o que muitas vezes potencializa 0 imediatismo e 0 aligeiramento da formação profissional, deixando em segundo plano a qualidade e as especificidades que demandam cada campo profissional. E, como consequências desse processo, originam-se a competitividade exacerbada e a fragmentação de uma devida categoria profissional.

\section{Práticas discursivas em torno da formação continuada do professor}

Fairclough (2001), ao usar o termo discurso, propõe considerar o uso da linguagem como forma de prática social e não como atividade puramente individual. Isso implica uma relação dialética entre o discurso e a estrutura social no sentido mais amplo e em todos os níveis: "pela classe e por relações sociais em um nível societário, pelas relações específicas em instituições particulares, como o direito ou a educação, por sistemas de classificação, por várias normas e convenções". (FAIRCLOUGH, 2001, p.91).

O discurso contribui, assim, para a constituição de todas as dimensões da estrutura social que, direta ou indiretamente, o moldam e o restringem: suas próprias normas e convenções, como também relações, identidades, instituições que Ihes são subjacentes.

Fairclough (2001) apresenta dois aspectos dos efeitos construtivos do discurso que correspondem a funções da linguagem e dimensões de sentido que coexistem e integram em todo o discurso. São eles: a construção do que variavelmente é referido como identidades sociais e posições de sujeito e a construção das relações entre as pessoas e a construção de sistemas de conhecimento e crença. 
No que diz respeito à função identitária, esta se relaciona aos modos pelos quais as identidades sociais são estabelecidas no discurso. Sendo assim, a prática discursiva é constitutiva tanto de maneira que "contribui para reproduzir a sociedade (identidades sociais, relações sociais, sistemas de conhecimentos e crenças) como também contribui para transformá-la." (FAIRCLOUGH, 2001, p. 92).

Como exemplo de prática discursiva o autor discorre:

As identidades de professores e alunos e as relações entre elas, que estão no centro de um sistema de educação, dependem da consistência e da durabilidade de padrões de fala no interior e no exterior dessas relações para sua reprodução. Porém, elas estão abertas a transformações que podem originar-se parcialmente no discurso: na sala de aula, do parquinho, da sala dos professores, do debate educacional, e assim por diante. (FAIRCLOUGH, 2001, p.93).

Sendo assim, o que torna a prática discursiva especificamente discursiva? Duas dimensões são mediadas para contrabalançar e tratar tal questão no trabalho. São elas: "a prática discursiva manifesta-se em forma linguística, parte da resposta está evidentemente na linguagem. [...] e a prática social (política, ideológica, etc.) é uma dimensão do evento discursivo que pode ser inteiramente constituída pela prática discursiva". (FAIRCLOUGH, 2001, p. 99).

Desta forma, o discurso proveniente de uma linha de ideal democrático, cujas premissas corroboram para a plena realização da atividade profissional, é gerado pela ideologia de mercado, em que a organização do trabalho torna-se prioridade para a produtividade. Segundo Foucault (1996), o discurso é o espaço em que saber e poder se articulam pois quem fala, fala de algum lugar, a partir de um direito reconhecido institucionalmente. Esse discurso que passa por verdadeiro, que veicula saber (o saber institucional) é gerador de poder.

Nesse sentido, as políticas que deliberam as diretrizes da formação continuada do professor, pautadas pelas concepções de competências e aperfeiçoamentos, repercutem vários emblemas em torno da profissionalidade exercida pelos sujeitos sociais em suas funções e cargos desempenhados. E, com isso, propagam-se representatividades bem como múltiplos sentidos e significados atribuídos ao papel de uma profissão e, principalmente, à importância do papel social desenvolvido pelo sujeito trabalhador. 
O professor é permeado por um conjunto de expectativas que envolvem tanto a problemática do seu trabalho, como por exemplo, a solução dos altos níveis do analfabetismo do país, como a perspectiva da equidade e inclusão social. O trabalho do professor converge paradigmas sociais que influem diretamente na forma como é construída sua identidade profissional, pela sociedade e, naturalmente, por ele mesmo.

Os exames de competências profissionais a eles referidos, que têm como um dos seus objetivos assegurar padrões de qualidade básicos para 0 exercício de suas atividades, são discursos imbuídos da ideologia da "adequação" e "adaptação" da competência profissional à atual sociedade neoliberal, cujo pressuposto refere-se a hierarquias das definições sociais e também profissionais. Para Cavalcante (2005, p.30), esse ideal ajusta-se ao conceito de competência profissional quando

retoma o conceito utilizado no tecnicismo nos anos 60 e atualizado na perspectiva da ideologia do mercado globalizado para quem o capitalismo é o único horizonte possível. A educação baseada nessa concepção deve trabalhar no sentido da adaptação dos indivíduos a essa estrutura social.

Deste modo, o discurso sobre quem não desenvolve as competências profissionais é o de que está fora do sistema produtivo social. Assim, se produz o efeito de sentidos de que somente quem detém "a qualificação profissional por competências" tem a possibilidade de conseguir êxito social e profissional.

\section{Construção identitária do sujeito professor}

Segundo Therborn (1980, p.03) a formação dos seres humanos por toda e qualquer ideologia envolve um processo que é simultaneamente de sujeição e qualificação. Nessa perspectiva o autor explica que:

A reprodução de qualquer organização social, seja uma sociedade exploradora ou um partido revolucionário, implica uma correspondência básica entre sujeição e qualificação. Aqueles que formam sujeitados a uma padronização particular das suas capacidades, para uma disciplina particular, são qualificados para dados papéis e capazes de levá-los a efeito. Mas, sempre há uma possibilidade inerente de que uma contradição possa se desenvolver entre essas qualificações. Novos tipos de qualificações podem ser requeridos e propiciados, novas habilidades que se chocam com as formas tradicionais de sujeição que se chocam com as provisões das qualificações ainda necessárias. Os efeitos de 
uma contradição entre sujeição e qualificação são a oposição e a revolta ou subdesempenho e a renúncia.

Transpondo esse processo de organização social com base na sujeição e qualificação para a conformação da crua praticalidade que caracteriza atualmente os programas de formação do professor tecnicamente orientados, surge a seguinte pontuação:

Os projetos para formação de professores, portanto, assumirão as formas do conhecimento pedagógico que tiverem sido legitimadas oficialmente pelos editores, faculdades de educação e distritos escolares. Com o passar do tempo tal conhecimento chega a ser visto não como um discurso político, mas como um senso comum inquestionável. Preocupações éticas e morais com os pressupostos embutidos no conhecimento são desprezadas e debates sobre política são removidos da arena moral e ética e transferidos para as questões técnicas sobre o que constitui uma instrução eficiente (KINCHELOE, 1997, p. $50)$.

Nesse sentido, a formação dos professores torna-se uma fonte de conformidade, um procedimento de ajustamentos no qual os pressupostos tecnicistas separam os professores de seus papéis na reconceitualização do ato de ensinar enquanto prática política e ética.

Nada ilustra melhor a perversidade das formas técnicas da educação dos professores como a explicitação de Bullough e Gitlin (1991) sobre os efeitos do treinamento tecnicista do professor:

Limita a visão da cognição do professor, que reduz o ato intelectual de ensinar a uma mera técnica. Os professores tornam-se seguidores de regras, leitores de livros-guias e são desencorajados a se engajarem em atos interpretativos. A seguir, um individualismo radical é criado para colocar os futuros professores uns contra os outros numa competição por notas, elogios de supervisores, recursos instrucionais e ideias e, naturalmente, por posições nas escolas. Mais importante ainda, esta ética individualista mascara os interesses comuns dos professores e obscurece a necessidade de uma ação coletiva dos professores na luta pela mudança educacional.

Esta visão metodológica das formas sobre as quais se concerne à formação do professor baseada principalmente nos conceitos de qualificação, certificação e competências profissionais do professor, ignora os contornos através dos quais a identidade individual é estruturada. Nossas subjetividades são formadas pelas forças culturais de classe, gênero, etnias, tais fatores estão além do nosso poder de revertê-las, assim como elas constroem limites e 
possibilidades em nossas várias relações. Elas ajudam a moldar o tipo de amigos que temos; o trabalho que fazemos e as companhias que escolhemos. Nossas interações com nossas famílias, religiões, locais de trabalho e, naturalmente, com as escolas ajudam a moldar nossa identidade.

Assim sendo, de que forma é construída a identidade do professor? Quais discursos permeiam a identidade profissional docente? Questões como essa, de natureza e propósito social e, por isso, política, remete à compreensão da constituição do indivíduo-sujeito, neste caso, especificamente, se faz necessário compreender a mobilização dos novos discursos que darão suporte à compreensão do sujeito professor.

Segundo Almeida (2008), Althusser define a expressão "forma-sujeito" para todo indivíduo humano, isto é, social, que só pode ser agente de uma prática revestindo-se da forma de sujeito, forma da existência histórica de qualquer indivíduo, agente de práticas sociais. A autora ainda diz que ao se constituir sujeito, o sentido é constituído, embora o sujeito não possa ser pensado como fonte do seu dizer. Ele exerce um papel efetivo na produção do discurso, desdobrando as formações discursivas que estão sempre em constante movimento. Assim, não se pode pensar em discurso, sujeito e sentido sem pensar em ideologia. Toda prática discursiva está inserida no complexo contraditório-desigual-sobredeterminado das formas discursivas que caracterizam a instância ideológica em condições históricas dadas. (PÊCHEUX, 1988, p.23).

O professor constitui-se sujeito de práticas sócio-históricas na medida em que vincula sentidos e formações discursivas sobre a sua função social. Esses desdobramentos exercem um papel fundamental na construção da identidade profissional do professor, pois estão revestidos de sentidos e significados ideológicos que compõem o discurso do exercício profissional bem sucedido.

Segundo Kincheloe (1997, p. 23) "a educação do professor, para o trabalho e no trabalho, está saturada com experiências cognitivas que encorajam tendências conservadoras, individualistas, competitivas e descontextualizadas da prática cotidiana do professor". Mclaren(1993) amplia este tema pontuando que a educação do professor tem sido considerada como a linguagem da eficiência e da lógica das técnicas de administração e 
esquemas de contabilidade, o que ocasiona a conformidade profissional e leva a resultados em termos de uniformidade do pensamento, a uma abordagem mecanicista da profissão e a uma inabilidade para intervir criticamente no mundo da prática escolar.

Desse modo, o discurso que permeia os sentidos atribuídos à atividade profissional do professor é o de que suas funções devem ser dirigidas com competências e qualificações condescendentes ao princípio norteador do sistema neoliberal, cujas ações voltam-se ao progresso da sociedade do conhecimento. Esse discurso delibera valores diretamente introduzidos na formação da identidade do sujeito professor.

Existe, assim, uma mensagem implícita nas diretrizes políticas educacionais que implementam programas e projetos de formação de professores que dizem o que os professores devem fazer, devendo ser cuidadosos sobre o pensar por eles mesmos.

\section{Conclusão}

A partir dos estudos realizados foi possível perceber os discursos que constroem uma política de subjetivações e valores diretamente encalçados na construção formativa da profissionalidade do professor.

Atualmente, a formação técnico-profissional e a qualificação e requalificação, segundo Frigotto (1998, p.48), produzem cidadãos que não lutam por seus direitos e pela desalienação do e no trabalho. Essas propostas sob o ideário das habilidades e competências para a empregabilidade, requalificação e reconversão, reduzem-se, dominantemente, a um invólucro de caráter ideológico.

Diante dessa linha ideológica, que ancora no profissional da educação a total responsabilidade em desenvolver e cumprir competências que viabilizem a qualidade na educação na perspectiva de potencializar a aprendizagem e a formação do aluno enquanto cidadão, surgem questões no atual contexto sobre a formação do professor em relação às suas funções, sentidos e representações que estão sendo produzidos. São elas: De que forma é pensado o professor? O que se espera do papel que tem a desempenhar? Quais os saberes que o professor deve dominar? 
Esses questionamentos refletem anseios e aspirações em relação à real necessidade de consubstanciar o que de fato torna a docência uma das mais complexas atividades de atuação profissional. Essa consolidação está imbricada pelo "saber-fazer", este movimento de ação-reflexão sobre a prática educativa.

Pensar a educação por uma vertente política, inerente a nós, sujeitos viventes e pensantes da nossa realidade, por uma visão de mundo que redimensione todos os aspectos e dispositivos que configuram essa realidade, é o primeiro passo para a consolidação de uma educação integradora e emancipadora. A academia, enquanto lócus de estudo e reflexão, torna-se essencial para a concretização de uma formação docente politizada que viabilize um pensar sobre os discursos a partir dos quais estão sendo construídas as práticas educativas que regulamentam o ofício do professor.

Não basta identificar as competências que o profissional possui se não há garantia da sua efetivação. É importante destacar ainda que os resultados dos testes devem ser uma referência para permitir ao professor condições que facilitem positivamente o exercício profissional, o que se dá no espaço concreto de sala de aula.

Nesse sentido, Kincheloe (1997) afirma que a formação do professor deve ser concebida conceitualmente em torno do cultivo do pensar sobre a docência. Sendo assim, "o papel do professor é conceitualizado como autônomo, livre da tirania do currículo institucionalmente imposto que permite uma curta latitude profissional" (KINCHELOE, 1997. p.48).

Dessa maneira, o sujeito professor que pensa a sua profissionalidade não se submeterá às formas com as quais vêm se constituindo atualmente os sentidos e discursos sobre a função e o desempenho docente em relação às definições autoritárias do papel do professor. Assim, a construção identitária do professor perpassa por uma reconceitualização crítica da educação em que a reflexão é uma forma de surgimento de consciência, uma atividade que dirige a atenção do professor para a inseparabilidade do pensamento e da política. 
Referências bibliográficas

ALMEIDA, C A. G. de. A política nacional de capacitação dos servidores: possível instrumento de gestão empresarial nas instituições de ensino superior? (Dissertação de Mestrado). São Paulo: PUC, 2001.

ALMEIDA. C. C. A formação docente na educação de jovens e adultos: uma análise discursiva. Dissertação. (Mestrado em Educação). Universidade Federal de Alagoas, 2008.

BULLOUGH, R e GITLIN. Educação e desenvolvimento das comunidades. In: R. TABCHNICK e K. ZEICHNER. Questões e prática no Inquérito. Nova York: Falmer. 1991.

CAVALACANTE. M. do S. A. de O. As malhas de discursos (re) veladoras. Maceió. EDUFAL, 2005.

DAVININI, M. C. A formação docente em questão. Buenos Aires: Paidós, 1995.

DELORS, J. A educação ou a utopia necessária. In: RELATÓRIO PARA A UNESCO DA COMISSÃO INTERNACIONAL SOBRE EDUCAÇÃO PARA O SÉCULO XXI. Educação: um tesouro a descobrir. São Paulo: Cortez; DF: MEC: UNESCO, 2004.

DEWEY. J. Como pensamos. 3ª Ed. São Paulo: Ed. Nacional, 1959.

FIDALGO, N. L. R. Processo de Individualização e Desenvolvimento de competências: implicações para a formação do trabalhador. 1. ed. Belo Horizonte: Programa de Pós-graduação em Educação da UFMG, 2003.

FAIRCLOUGH, N. Discurso e mudança social. Brasília: Editora da UnB, 2001.

FOUCAULT, M. A ordem do discurso. São Paulo: Loyola, 1996.

FRIGOTTO, G. Educação, crise do trabalho assalariado e do desenvolvimento: teorias em conflito. Educação e crise do trabalho: perspectivas de final de século. Petrópolis, RJ: Vozes, 1998.

GÓMEZ, A. P. O pensamento prático do professor - a formação do professor como profissional refletivo. In: NÓVOA, A. (Coord). Os professores e a sua formação. Lisboa: Publicações Don Quixote/ IIE, 1992. 
KINCHELOE, J. L. A formação do professor como compromisso político. Mapeando o pós-moderno. Porto Alegre: Artes Médicas, 1997.

LIMA, A. Certificação: A visão do M.T.E. (Ministério do Trabalho e Emprego), Texto de apoio à exposição do autor no Conselho Nacional de Educação - Brasília, maio, 2003.

MCLAREN, P. Multiculturalism and the Postmodern Critique: towards a pedagogy of resistance and transformation. Cultural Studies, vol.7, n. 1, p.118-146, jan. 1993.

MORAES. C.; NETO, S. Educação, Formação Profissional e Certificação de conhecimentos: considerações sobre uma política pública de certificação profissional. Educação e Sociedade. Campinas, vol.26, n. 93, p.1435-1469, Set./Dez. 2005.

MOURÃO, A R B. A Qualificação como construção social e os desafios da Educação. Amazônida (UFAM), Manaus, v. 1, p. 107-118, 2003.

PÊCHEUX, M. Semântica e discurso: uma crítica a afirmação do óbvio. Tradução ErniOrlandi. Campinas, Editora da UNICAMP. 1988.

RIBAS, M.H. A formação Contínua e a Construção da Competência Pedagógica: trajetos e projetos. (Dissertação de Mestrado).Pontifícia Universidade Católica de São Paulo, 1997.

SHIROMA, Eneida. Um fantasma ronda o professor: a mística da competência. In: MORAES, Célia M (org). Produção de conhecimento e políticas de formação docente. Rio de Janeiro. DPEA, 2003.

SCHÖN, D. A. Formar professores como profissionais reflexivos. In: Nóvoa, A. Os professores e sua formação. Lisboa: Publicações Dom Quixote/lIE, 1992.

THERBORN, Göran. The Ideology of Power and the Power of Ideology. London: Tradução: Jair Pinheiro e Lúcio Flávio de Almeida, 1980. 
Artigo recebido em: 19/12/2013

Artigo avaliado em: 10/02/2014

Sobre a autora:

Discente do Programa de Pós-graduação em Crítica Cultural, Departamento de Educação, UNEB-Campus II. Bolsista na modalidade de mestrado pela FAPESB. 